\title{
Identical de novo mutation at the D4F104S1 locus in monozygotic male twins affected by facioscapulohumeral muscular dystrophy (FSHD) with different clinical expression
}

Rossella Tupler, Laura Barbierato, Mirella Memmi, Caroline A Sewry, Domenico De Grandis, Paola Maraschio, Luciano Tiepolo, Alessandra Ferlini

\begin{abstract}
Facioscapulohumeral muscular dystrophy (FSHD) is a progressive hereditary neuromuscular disorder, transmitted in an autosomal dominant fashion. Its clinical expression is highly variable, ranging from almost asymptomatic subjects to wheelchair dependent patients. The molecular defect has been linked to chromosome 4q35 markers and has been related to deletions of tandemly repeated sequences located in the subtelomeric region detected by probe p13E-11 (D4F104S1).

We describe a pair of monozygotic male twins affected by FSHD, carrying an identical de novo p13E-11 EcoRI fragment of paternal origin and showing great variability in the clinical expression of the disease, one being almost asymptomatic and the other severely affected. Their medical history was the same, with the exception of an anti-rabies vaccination performed at the age of 5 in the more severely affected twin. We hypothesise
\end{abstract}

that the vaccination might have triggered an inflammatory immune reaction contributing to the more severe phenotype. $(\Im$ Med Genet 1998;35:778-783)

Keywords: FSHD; monozygotic twins

Facioscapulohumeral muscular dystrophy (FSHD) is a neuromuscular disorder characterised by progressive weakness and atrophy of the facial and shoulder girdle muscles, with subsequent involvement of the abdominal, foot extensor, upper arm, and pelvic girdle muscles. ${ }^{12}$ The incidence of the disease, which is transmitted in an autosomal dominant fashion, is estimated as 1 in 20000 . Its penetrance is considered almost complete and in $95 \%$ of patients onset is by the age of 20 years. Its clinical expression is highly variable even within the same family, ranging from nearly asymptomatic to wheelchair dependent patients. $^{3}$

Pathological alterations in muscle biopsies are consistent with a primary defect of muscle
Biologia Generale e Genetica Medica, University of Pavia, CP 217, 27100 Pavia, Italy

R Tupler

L Barbierato

M Memmi

P Maraschio

L Tiepolo

Neuromuscular Unit, Hammersmith Hospital, London, UK

C A Sewry

A Ferlini

Divisione di

Neurologia,

Arcispedale S Anna,

Ferrara, Italy

D De Grandis

Correspondence to: Dr Tupler.

Received 14 February 1997 Revised version accepted for publication 26 February 1998
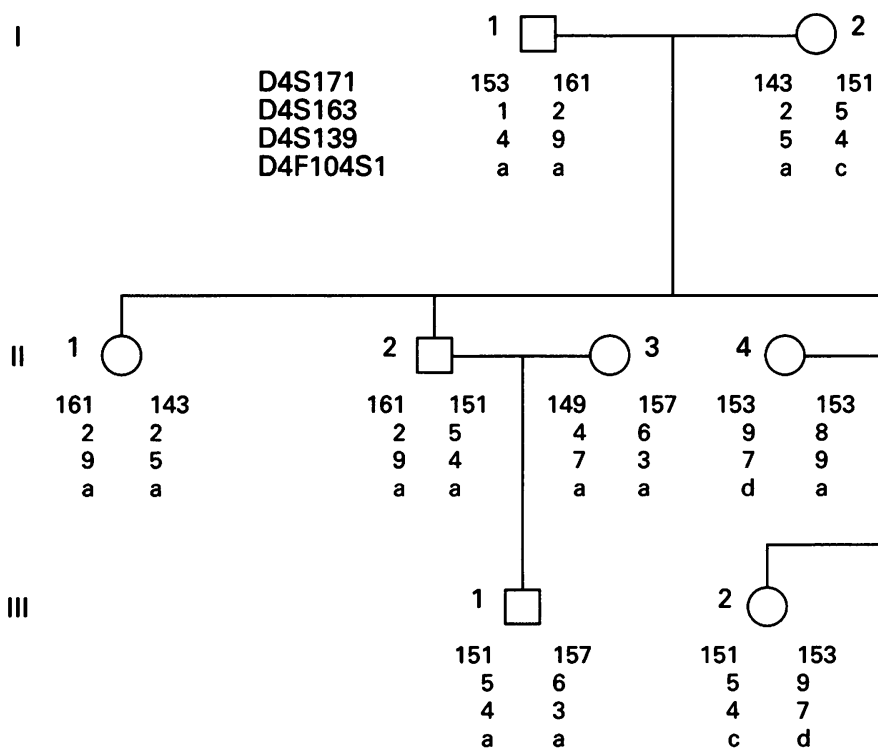

Figure 1 Three generation pedigree of the family. The haplotypes obtained with four different $4 q 35$ marker loci (D4S171, D4S163, D4S139, D4F104S1) are indicated below the symbols. A recombination event between loci D4S139 and D4F104S1 has occurred during maternal meiosis in II.2. III. 3 shows the paternal haplotype carrying the de novo mutated allele at the D4F104S1 locus and indicates that the mutational event has occurred during gametogenesis in the grandfather or postzygotically, before the twinning, being associated with alleles 153, 1, and 4 at D4S171, D4S163, and D4S139, respectively. Locus D4F104S1 allele size range: a, larger than $48 \mathrm{~kb} ; b$, between 38 and $48 \mathrm{~kb} ; c-d$, between 33 and $38 \mathrm{~kb}$; $e$, smaller than $23 \mathrm{~kb}$. Closed symbols indicted the affected monozygotic twins (II. 5 and II.6). 

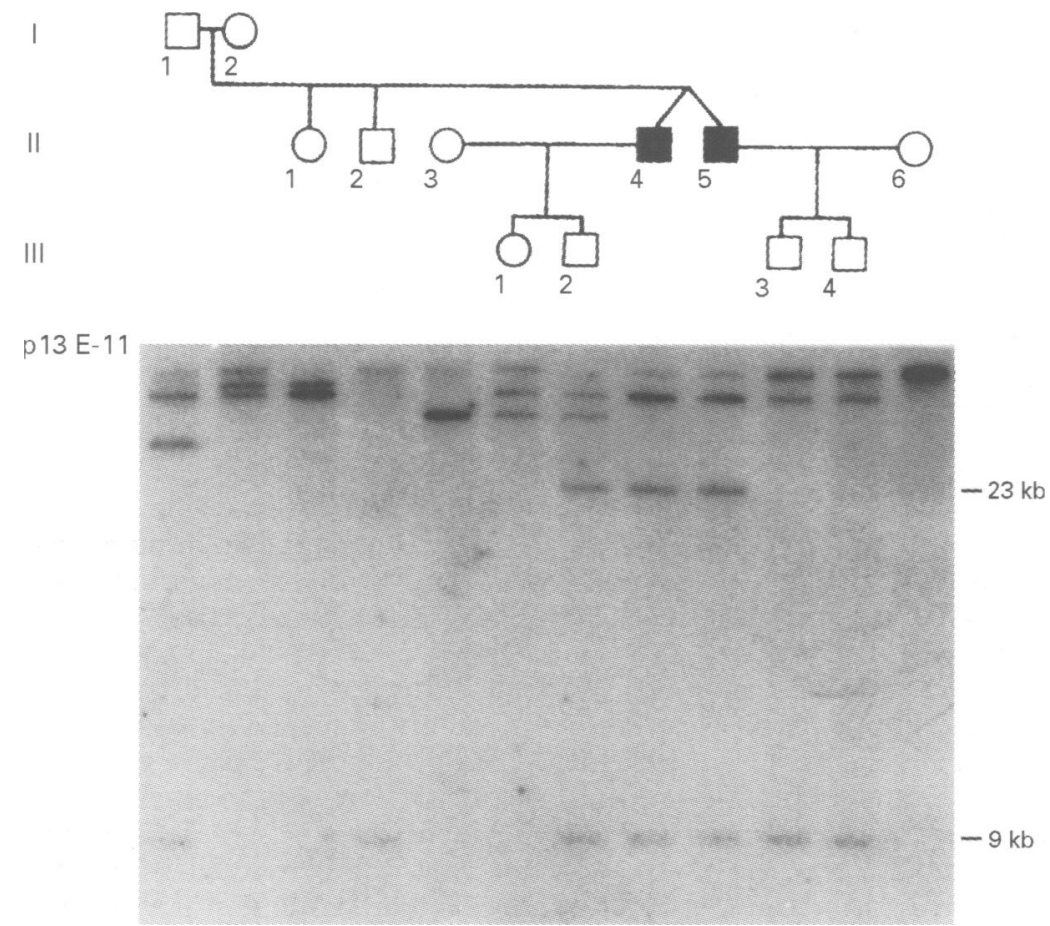

Figure 2 Southern blot analysis of EcoRI digested DNA with probe $13 E-11$ shows the presence of a de novo allele, shorter than $23 \mathrm{~kb}$, in both twins (II. 4 and II.5) and in one son of II. 4 (III.2). Subjects affected by FSHD are indicated by closed symbols.

fibres, including variation of fibre diameter, centrally placed nuclei, occasional necrosis of muscle fibres, and increased endomysial and perimysial connective tissue. Occasionally, mononuclear cells may be detected ${ }^{1}$ and inflammatory changes have been described in $40-80 \%$ of FSHD patients. ${ }^{45}$

The FSHD locus has been mapped by genetic linkage analysis to the chromosome $4 \mathrm{q} 35-\mathrm{qter}$ region. ${ }^{6-12}$ Specific deletions of chro-

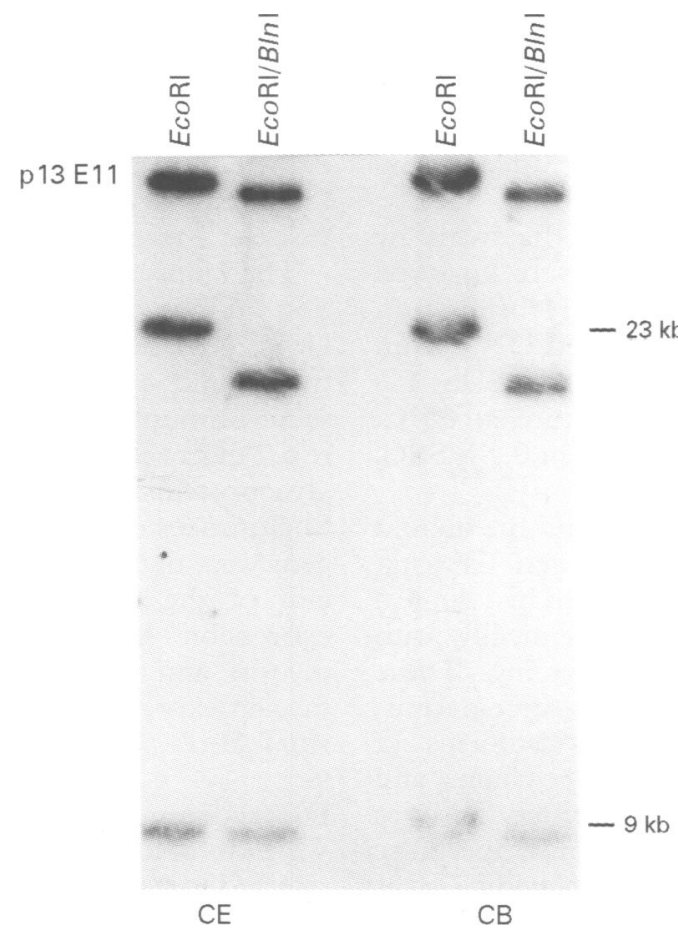

Figure 3 Southern blot analysis of EcoRI and

EcoRI/BlnI digested DNA from the twins (CE, the severely affected one, and $C B$, the almost asymptomatic one) with probe p13E-11. Chromosome $4 q 35$ alleles are preserved after double digestion in both. mosome $4 \mathrm{q} 35$ have been detected using probe p13E-11 (D4F104S1). ${ }^{13}$ These deletions occur in highly polymorphic EcoRI fragments displaying a VNTR-like structure with a $3.3 \mathrm{~kb}$ tandem repeat unit. ${ }^{14}$ It has been postulated that deletions of the tandemly repeated unit, which have been localised to the subtelomeric heterochromatin, may be responsible for the cis inactivation of the FSHD gene by a mechanism similar to the positional effect variegation. ${ }^{15}$ Alternatively this structural modification could influence the regulation of gene transcription. However, no candidate gene has yet been identified in the FSHD region. Recently, probe p13E-11 has shown that fragments with a similar $3.3 \mathrm{~kb}$ repeat polymorphism occur on chromosome 10 qter $^{16}$ and that $10 \%$ of the $10 \mathrm{q}$ linked polymorphic fragments are smaller than $35 \mathrm{~kb}$, a size comparable to the $4 \mathrm{q}$ deleted fragments observed in FSHD patients. ${ }^{17}$ The $10 \mathrm{q}$ linked fragments are distinguishable from the $4 \mathrm{q}$ linked fragments by double digestion of the DNA with $E c o$ RI and $B \ln I .^{18}$

To date three sets of monozygotic twins affected by FSHD have been described; one pair was discordant for the disease ${ }^{19}$ and only the affected twin showed a deleted EcoRI fragment at the D4F104S1 locus. ${ }^{20}$ In the two other sets FSHD was familial and dominantly inherited in the concordant twins. ${ }^{21}$ Here we describe two monozygotic male twins affected by FSHD, carrying an identical p13E-11 EcoRI fragment of "de novo" origin and showing a great difference in the clinical expression of the disease.

\section{Materials and methods}

PATIENTS

The twins, $\mathrm{CE}$ and $\mathrm{CB}$, were born at term on 19 July 1952 after an uneventful pregnancy and a normal delivery. They were raised together and their psychomotor development was normal. The twin II.6 (fig 1) at the age of 5 years underwent a rabies vaccination, at that time (1957) performed with a nerve tissue vaccine (NTV). He had complained of weakness at the age of 12 years, followed by progressive difficulty in his motor performance, hypotrophy of the biceps, and upward slanting of the scapulae. At the age of 32, muscle weakness extended to the lower limbs, mostly to the gluteus muscles. He showed a marked lordotic posture and had difficulty in getting up from the floor. Neurological examination at the age of 40 showed hypotonia and wasting in the upper limbs and quadriceps and a marked lordosis. His gait was unstable with a tendency to fall frequently. He was unable to walk on tiptoe. The facial muscles were involved with inability to blow out the cheeks and whistle. Distal power was conserved, although mildly reduced in his hands. He has two sons (III.4 and III.5, fig 1), aged 15 and 9 years, who are completely asymptomatic with a normal neurological examination.

Twin II.5 (fig 1) was almost asymptomatic. At the age of 15, neurological examination showed a mild hyperlordotic posture, upward slanting of the scapulae, and mild hypotrophy of the biceps. At the most recent examination 


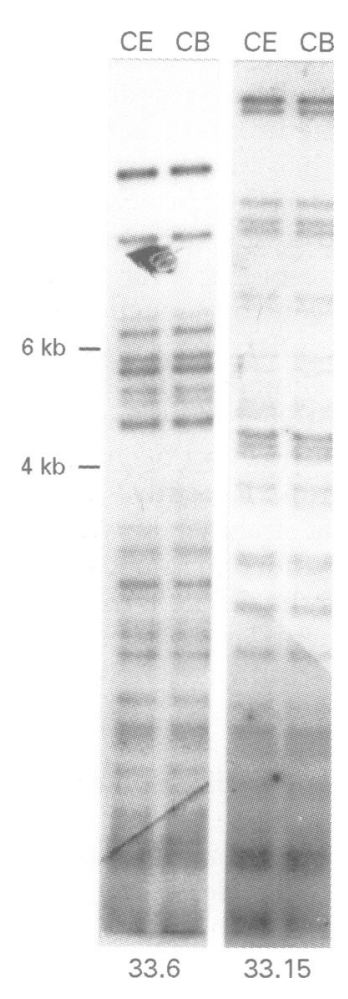

Figure 4 DNA fingerprints of the twins using probes 33.6 and 33.15 confirm their genetic identity. in 1996, clinical progression had not occurred. No sign of muscular dystrophy was present in the lower limbs. He was still able to whistle but showed a mild inability to screw his eyes up tightly. He has two children (III.2 and III.3, fig 1 ), aged 14 and 11 years, who are completely asymptomatic, with the exception of mild winging of the scapulae in both.

The family history was negative for the presence of neuromuscular diseases on the basis of clinical history. The twins' father (I.1) was asymptomatic. His neurological examination showed mild winging of the scapulae without weakness. His father has been reported to show the same posture and gait. No clinical records are available for him.

\section{MOLECULAR TECHNIQUES}

DNA extracted from peripheral leucocytes of all subjects was studied for allele segregation at loci D4S163 (probe LILA5/PstI), D4S139 (probe pH30/TaqI), and D4F104S1 (p13E-11/ $E c o \mathrm{RI})$ using standard electrophoresis and Southern blot techniques. The size of the fragments at D4F104S1 was allocated by comparison with high molecular weight DNA standards (Gibco BRL) of size 8.3, 8.6, 10.1, 12.2, $15.0,17.1,19.4,22.6,24.8,29.9,33.5,38.4$, and $48.5 \mathrm{~kb}$ on the same gel. The de novo p13E-11 EcoRI fragments were assigned to chromosome 4 by double digestion with $E c o$ RI/BlnI

(CA)n dinucleotide Mfd22 (D4S171 locus) was tested using published primer sequences. ${ }^{22}$ PCR amplification was carried out in a total volume of $15 \mu \mathrm{l}$ containing $100 \mathrm{ng}$ of genomic DNA in $50 \mathrm{mmol} / 1 \mathrm{KCl}, 50 \mathrm{mmol} / \mathrm{l}$ Tris- $\mathrm{HCl}$ (pH 9.0), $7 \mathrm{mmol} / 1 \mathrm{MgCl}_{2}, 5 \mathrm{pmol}$ of each primer, $0.2 \mathrm{mmol} / 1 \mathrm{dNTPs}, 0.2 \mathrm{mg} / \mathrm{ml} \mathrm{BSA}, 16$ $\mathrm{mmol} / \mathrm{l}\left(\mathrm{NH}_{4}\right)_{2} \mathrm{SO} 4$, and $1 \mathrm{U}$ of Taq polymerase (SuperTaq, HT Biotechnology Ltd, Cambridge, UK). PCR conditions consisted of 27 cycles of one minute at $95^{\circ} \mathrm{C}$, two minutes at $55^{\circ} \mathrm{C}$, and one minute at $72^{\circ} \mathrm{C}$ for each cycle. The PCR products were run on a denaturing $6 \%$ polyacrylamide gel in $0.5 \times \mathrm{TBE}$.

Monozygosity was proven in the twins by using DNA typing. Forty loci were analysed with probes 33.6 and $33.15 .{ }^{23}{ }^{24}$ Hybridisation was carried out on Hinfl digested DNA from both twins in a $0.5 \mathrm{~mol} / 1 \mathrm{NaPO}_{4}, 7 \%$ SDS, $1 \%$ albumin, and hybridisation mixture at $65^{\circ} \mathrm{C}$. Washes were performed at $60^{\circ} \mathrm{C}$ in $0.1 \times \mathrm{SSC}$, $0.1 \%$ SDS.

Muscle biopsies were taken from the deltoid muscle and frozen in liquid nitrogen. Cryostat sections were stained with standard histological techniques and immunocytochemically with antibodies to a variety of proteins. These included dystrophin, spectrin, sarcoglycans, utrophin, fast, slow, and fetal isoforms of myosin, laminin, $\alpha 1, \alpha 2, \beta 1$, and $\gamma 1$ chains, and HLA class I antigens. Primary antibodies were incubated for 30 minutes at room temperature and visualised with a biotin-streptavidin-Texas red method, as previously described..$^{25}$

\section{Results}

Molecular analysis of the D4S171, D4S163, D4S139, and D4F104S1 loci was extended over three generations in the family, including the parents and the children of the twins (fig 1). Probe p13E-11 showed a de novo fragment of about $23 \mathrm{~kb}$ at the D4F104S1 locus in both twins, which was transmitted to one child (III.2, fig 2). Haplotype segregation studies (fig 1) indicated that the de novo fragment originated from a mutational event occurring during paternal gametogenesis, since in III.3 the grandpaternal haplotype is associated with the de novo fragment. Haplotype analysis also showed that in subject II.2, a recombination event between D4S139 and D4F104S1 had occurred during maternal gametogenesis. We were able to confirm the origin of the de novo p13E-11 EcoRI fragments at the chromosome 4 D4F104S1 locus by double digestion with $E c o \mathrm{RI} / B \ln \mathrm{I}$ (fig 3). As reported by Deidda et $a{ }^{18}$ the $10 \mathrm{q}$ linked fragments are distinguishable from the $4 \mathrm{q}$ linked fragments by double digestion of the DNA with EcoRI and $B \ln \mathrm{I}$. After this double digestion p13E-11 $4 \mathrm{q}$ linked fragments appear $3 \mathrm{~kb}$ smaller than the $E c o$ RI fragments, whereas the $10 \mathrm{q}$ linked fragments are not detectable after electrophoresis at the standard conditions, owing to a high number of $B \ln I$ restriction sites in the $10 \mathrm{q}$ repeat units.

Using the two minisatellite probes $(33.15$ and 33.6) monozygosity (fig 4) was confirmed, compared to a probability of chance association of $<<5 \times 10^{-19}$. Paternity was confirmed with traditional and molecular markers (probability of paternity $\mathrm{W}=99.999 \%$ according to Essen-Moller ${ }^{26}$ ).

The muscle biopsy of the asymptomatic twin showed no significant features. There was no abnormality in fibre size, no increase in connective tissue, and no structural changes. Immunocytochemistry also showed no abnormalities and the expression of all proteins studied was normal. Fetal myosin, usually associated with regenerating fibres and thus an indicator of previous muscle damage, was not detected in any fibres. Expression of HLA class I antigens was also normal and confined to the vascular components (fig $5 \mathrm{~A}, \mathrm{C}, \mathrm{E}$ ).

The biopsy of $\mathrm{CE}$, in contrast, showed variation in fibre size with several very small fibres. Occasional necrotic fibres, a little connective tissue, and a few infiltrating cells were also seen. Immunocytochemical labelling for spectrin, dystrophin, the dystrophin associated glycoproteins, and laminin chains was normal. Slight traces of utrophin and HLA class I antigens were detected in some mature fibres. Several of the small fibres also showed HLA expression but these also expressed fetal myosin and were probably immature. Fetal myosin expression was mainly confined to the small fibres (fig 5B, D, F).

\section{Discussion}

We have studied a pair of monozygotic twins referred to us for clinical and molecular assessment of FSHD. They are genetically identical and both show a de novo p13E-11 EcoRI fragment associated with chromosome 4 . Neurological examination of their parents was normal, with no sign of muscular dystrophy. 

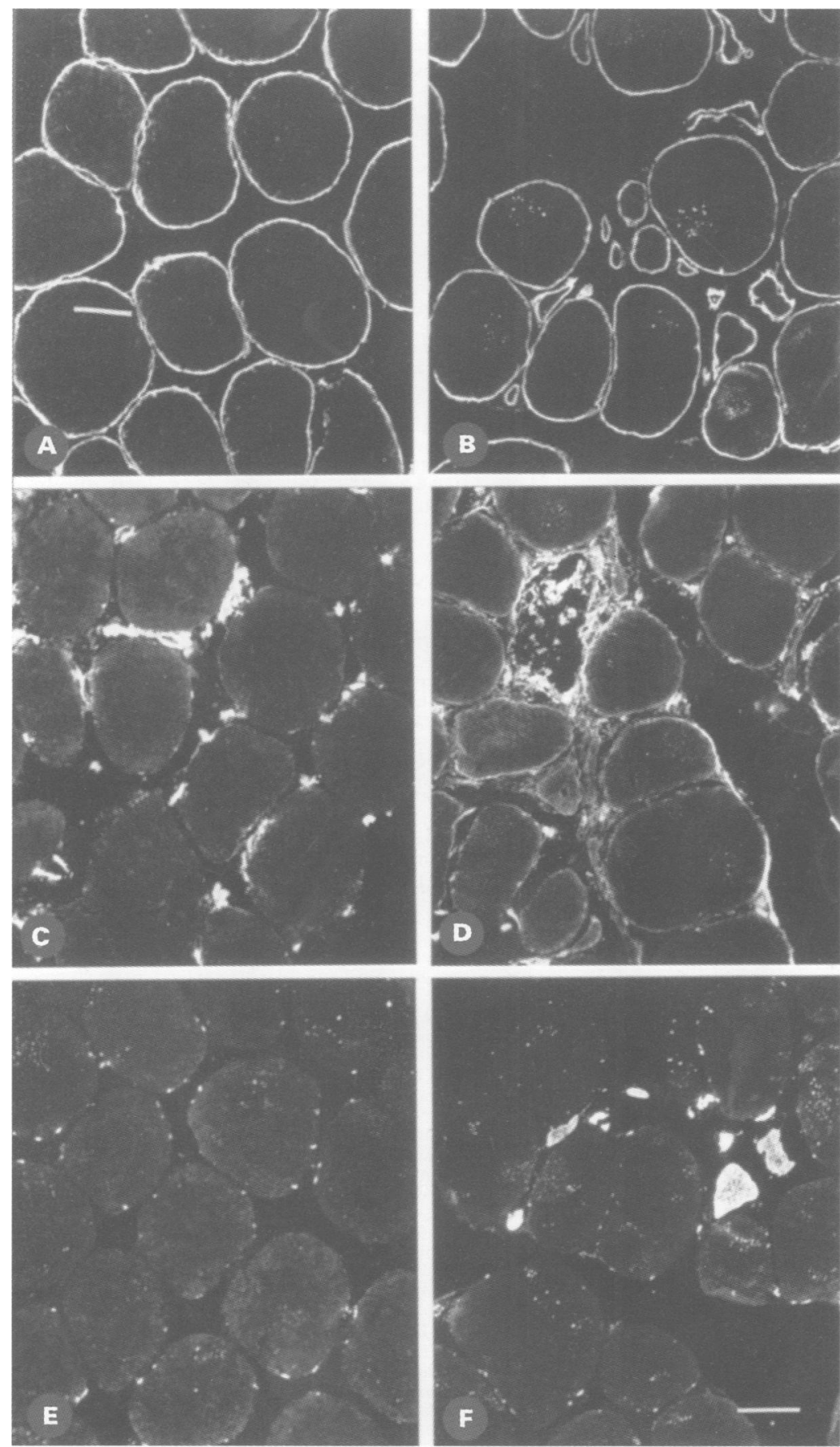

Figure 5 Immunolabelling of the biopsies from $C B(A, C, E)$ and $C E(B, D, F)$ with antibodies to $C$-terminal dystrophin $(A, B), H L A$ class $I$ antigens $(C, D)$, and fetal myosin $(E, F)$. Note the greater pathology in $C E$ and the very small fibres that express fetal myosin and HLA class I antigens, suggesting that they are regenerating fibres. Note also the mild expression of HLA class I on mature fibres in $C E$ but its absence from fibres in $C B$ (the fine peripheral dots in $E$ and $F$ are the result of autofluorescence of lipofuscin). Bar $=50 \mu \mathrm{m}$.

Haplotype analysis of the family showed that the de novo rearrangement in the D4F104S1 locus had occurred in paternal gametogenesis or postzygotically in the paternal chromosome 4 before the twinning and that the mutated fragment was subsequently transmitted to one of the grandchildren (III.3, fig 1). The genetic identity of the two twins does not match their clinical picture, with twin CB being almost asymptomatic and CE severely impaired.

To our knowledge, three sets of monozygotic twins affected by FSHD to a different extent have been reported. In one pair, molecular analysis of the D4F104S1 locus showed the presence of a de novo short p13E-11 EcoRI fragment only in the affected twin, presumably owing to a postzygotic mutation and thus explaining the phenotypic differences between the two brothers. ${ }^{19} 20$ The two other pairs were monozygotic female twins with different clinical expression and carrying a similar EcoRI fragment at the D4F104S1 locus. Other chromosome 4q35 specific markers were not tested. No specific anamnestic records were reported. On account of the gender of the patients, the authors considered that $\mathrm{X}$ inactivation might potentially influence the expression of the disease in these subjects. ${ }^{21}$ This hypothesis does not apply to our cases as the monozygotic twins described here are male. They carry the same mutated fragment but show a different phenotype.

Clinically discordant monozygotic twins for various diseases have often been reported. Discordance is particularly evident, for example, in Wiedeman-Beckwith syndrome (WBS); out of the eight cases of monozygotic twins described, ${ }^{27-29}$ seven were discordant for the expression of this syndrome, showing one twin with many classical manifestations of the disease and the other having few or none. Minor anomalies observed in most of the normal co-twins were ascribed to the presence of mild forms of WBS and have been explained as a consequence of either environmental factors ${ }^{27}$ or somatic mosaicism. ${ }^{28}$ In our case a postzygotic mutation, occurring before the twinning and leading to a different extent of mosaicism in the two brothers, might account for the differences in the clinical manifestation of the muscular dystrophy. However, qualitative evidence of mosaicism, as shown by the presence of an additional less intense band, was not detected by probe p13E-11..$^{30-32}$

Considerable phenotypic variability is described among FSHD patients with wide variation in the age of onset and in the rate of progression as well as in the extent of specific muscle involvement. In an attempt to explain these clinical differences, Lunt et $a l^{3}$ studied a large group of familial cases and found a correlation between the p13E-11 EcoRI fragment size and age at onset or progression of muscle impairment. The smallest fragments were associated with the earliest age of onset and with earlier use of a wheelchair. The authors proposed that D4F104S1 fragment size determines a part of the variance in age of onset and eventual severity of FSHD. Furthermore, the analysis of the age at onset of clinical signs in patients from multigenerational families suggested that anticipation could occur in FSHD. ${ }^{34}$ In standardised genotype-phenotype studies it has been shown that the degree of clinical severity present in the parent is significantly lower when compared to the offspring, supporting the hypothesis of anticipation in FSHD. ${ }^{35}$ Nevertheless, we have studied families in which almost asymptomatic subjects and wheelchair dependent patients were present within the same generation, with affected members carrying the identical EcoRI fragment (unpublished observations). In this respect, FSHD also differs from those hereditary 
diseases characterised by meiotic and mitotic instability resulting in an expansion of triplets interfering with gene expression. ${ }^{36}$ In FSHD patients, deletions of tandem repeats occur in the heterochromatic subtelomeric region of chromosome 4q. Structural changes of the heterochromatin could interfere with the expression of genes located proximally to this region. However, this hypothesis does not explain the clinical variability of the disease within the same family, being the deleted fragments transmitted without any modification of their length. To clarify the basis of the great variance in the levels of expression of the disease, a more complex mechanism should be considered. In this respect, twins studies could be very useful in order to separate the aspects linked to the genetic background, and therefore to the natural history of the disease, from those related to environmental factors that might have influenced the phenotype.

There was no difference in the clinical history of our patients, with the exception of an anti-rabies vaccination performed with a nerve tissue vaccine (NTV) in CE at the age of 5 years. Furthermore, their father and paternal grandfather had sloping shoulders, causing an FSHD-like posture, suggestive of the presence of an almost asymptomatic form of the disease in the previous generations. If this were the case, linkage analysis would confirm the segregation of FSHD with the putative $4 \mathrm{q} 35$ locus, while the de novo EcoRI fragment of paternal origin present in the twins would represent a mutational event independent of the transmission of the disease and not interfering with its clinical severity.

Inflammatory pathological findings are common in several primitive muscular dystrophies. In view of a possible role of inflammation in the clinical picture of FSHD, Arahata et $a l^{37}$ analysed inflammatory mononuclear cells in FSHD muscle sections and in normal controls. They found that an increased number of necrotic fibres corresponds with an accumulation of inflammatory cells, and hypothesised that mononuclear cellular infiltrates may enhance muscle fibre damage. The muscle pathology in case CE shows features consistent with FSHD and no specific defects in protein expression were seen. It is interesting to note, however, that there was some expression of HLA class antigens in the muscle fibres. This is a common feature of inflammatory autoimmune myopathies. In our case, the anti-rabies vaccination administered to $C E$ could have triggered an inflammatory immune reaction that may have contributed to the more severe phenotype.

We thank Professor M Fraccaro and Dr G Perini for their helpful suggestions, Dr C Previderè for the paternity testing, Profesfor R R Frants for kindly providing the p13E-11 plasmid, and $M$ Gatti for her technical support. The financial support of the Telethon to project C18 (cell bank) is gratefully acknowledged. This work was supported by Telethon grants No 729. L Barbi-

1 Munsat TL. Facioscapulohumeral dystrophy and the scapuloperoneal syndrome. In: Engel AG, Banker BQ, eds. Myology. New York: McGraw-Hill, 1993:1220-32.

2 Padberg GW. Facioscapulohumeral disease revealed by the presence of an additional less intense band. MD thesis, Leiden ence of an additional less
University, Leiden, 1982.
3 Lunt PW, Harper PS. Genetic counselling in facioscapulohumeral muscular dystrophy. F Med Genet 1992;26:755-60. 4 Bodensteiner JB, Schochet SS. Facioscapulohumeral muscular dystrophy: the choice of a biopsy site. Muscle Nerve 1986;9:544-7.

5 Dubowitz V, Brooke MH. Muscle biopsies: a modern approach. London: Saunders, 1973:202-12.

6 Wijmenga C, Sandkuijl LA, Moerer P, et al. Genetic linkage map of facioscapulohumeral muscular dystrophy and five polymorphic loci on chromosome 4q35-qter. Am f Hum Genet 1992;51:411-15.

7 Mathews KD, Mills KA, Bosch EP, et al. Linkage localization of facioscapulohumeral muscular dystrophy (FHSD) in 4q35. Am $\mathcal{F}$ Hum Genet 1992;51:428-31.

8 Mills KA, Buetow KH, Xu Y, et al. Genetic and physical mapping on chromosome 4 narrows the localization of the gene for facioscapulohumeral muscular dystrophy (FSHD). Am ₹ Hum Genet 1992;51:432-9.

9 Gilbert JR, Stajich JM, Speer MC, et al. Linkage studies in facioscapulohumeral muscular dystrophy (FSHD). $\mathrm{Am} \mathcal{f}$ Hum Genet 1992;51:424-7.

10 Weiffenbach B, Bagley R, Falls K, et al. Linkage analyses of five chromosome 4 markers localizes the facioscapulofive chromosome 4 markers localizes the facioscapulo-
humeral muscular dystrophy (FSHD) gene to distal 4q35. Am f Hum Genet 1992;51:416-23.

11 Sarfarazi M, Wijmenga C, Upadhyaya M, et al. Regional mapping of facioscapulohumeral muscular dystrophy gene on 4q35: combined analysis of an international consortium. Am $\mathcal{F}$ Hum Genet 1992;51:396-403.

12 Upadhyaya M, Lunt P, Sarfarazi M, Broadhead W, Farnham J, Harper PS. The mapping of chromosome $4 \mathrm{q}$ markers in relation to facioscapulohumeral muscular dystrophy (FSHD). Am $\mathcal{f}$ Hum Genet 1992;51:404-10.

13 Wijmenga C, Hewitt JE, Sandkuijl LA, et al. Chromosome $4 \mathrm{q}$ DNA rearrangements associated with facioscapulohumeral muscular dystrophy. Nat Genet 1992;2:26-30.

14 van Deutekom JCT, Wijmenga C, van Tienhoven EAE, et al. FHSD associated DNA rearrangements are due to FHSD associated DNA rearrangements are due to
deletions of integral copies of a $3.2 \mathrm{~kb}$ tandemly repeated deletions of integral copies of a $3.2 \mathrm{~kb}$
unit. Hum Mol Genet 1993;2:2037-42.

15 Winokur ST, Bengtsson U, Feddersen J, et al. The DNA rearrangement associated with facioscapulohumeral muscular dystrophy involves heterochromatin-associated repetitive element: implications for a role of chromatin structure in the pathogenesis of the disease. Chrom Res 1994;2: 225-34.

16 Deidda G, Cacurri S, Grisanti P, Vigneti E, Piazzo N, Felicetti $L$. Physical mapping evidence for a duplicated region on chromosome 10 qter showing high homology with the
facioscapulohumeral muscular dystrophy locus on chromosome 4qter. Eur $₹$ Hum Genet 1995;3:155-67.

17 Bakker E, Wijmenga C, Vossen RHAM, et al. The FSHD linked locus D4F104S1 (p13E-11) on 4q35 has an homolinked locus D4F104S1 (p13E-11) on 4q35 has an
logue on 10qter. Muscle Nerve 1995;suppl 2:39-44.

18 Deidda G, Cacurri S, Piazzo N, Felicetti L. Direct detection of $4 \mathrm{q} 35$ rearrangements implicated in facioscapulohumeral
ond muscular dystrophy. $\mathcal{f}$ Med Genet 1996;33:361-5.

19 Tawil R, Storvick D, Feasby TE, Weiffenbach B, Griggs RC. Extreme variability of expression in monozygotic twin with FSH muscular dystrophy. Neurology 1993:43:345-8.

20 Tawil R, Storvick D, Weiffenbach B, Altherr MR, Feasby TE, Griggs RC. Chromosome 4q DNA rearrangement in monozygotic twins discordant for facioscapulohumera muscular dystrophy. Hum Mutat 1993;2:492-6.

21 Griggs RC, Tawil R, McDermott M, Forrester J, Figlewicz D, Weiffenbach B. Monozygotic twins with facioscapulohumeral dystrophy (FSHD): implication for genotype/ phenotype correlation. Muscle Nerve 1995; suppl 2:50-5.

22 Whenotype correlation. Muscle Nerve 1995; suppl 2:50-5. hybrid map of 15 loci on the distal long arm of hybrid map of 15 loci on the distal long arm of chromosome 4, the region containing the gene responsible for facioscapulohumeral

Genet 1993;53:874-80.
23 Jeffreys AJ, Wilson V, Thein SL. Individual-specific "fingerprints" of human DNA. Nature 1985;316:76-9.

24 Gill P, Jeffreys AJ, Werrett DJ. Forensic application of DNA "fingerprints". Nature 1985;318:577-9.

25 Sewry CA, Philpot J, Mahony D, Wilson LA, Muntoni F, Dubowitz V. Expression of laminin subunits in congenita muscular dystrophy. Neuromusc Disord 1995;5:307-16.

26 Essen-Moller E. Die Beweiskraft der Ahnlichkeit in Vaterschafts-nachweis: Theoretische Grundlagen. Mitt Antropol Ges 1938;68:9-53.

27 Olney AH, Buehler BA, Waziri M. Wiedemann-Beckwith syndrome in apparently discordant monozygotic twins. $\mathrm{Am}$ 7 Med Genet 1988;29:491-9.

28 Litz CE, Taylor KA, Qiu JS, Pescovitz OH, de Martinville B. Absence of detectable chromosomal and molecular abnormalities in monozygotic twins discordant for the Wiedemann-Beckwith syndrome. Am F Med Genet 1988; 30:821-33.

29 Estabrooks LL, Lamb AN, Kirman HN, et al. BeckwithWiedemann syndrome in twins with a duplication of chromosome 15(q11.2-q13)mat. Am f Hum Genet Suppl 1989; 45:A75.

30 Weiffenbach B, Dubois J, Storvick D, et al. Mapping the facioscapulohumeral muscular dystrophy gene is complicated by chromosome $4 \mathrm{q} 35$ recombination events. Nat Genet 1993;4:165-9.

31 Upadhyaya M, Maynard J, Osborn M, Jardine P, Harper PS Germinal mosaicism in facioscapulohumeral muscular dystrophy (FSHD). Muscle Nerve Suppl 1995;2:S45-9.

32 Bakker E, Van der Wielen MJR, Ippel PF, Padberg GW, Frants RR, Wijmenga C. Diagnostic, predictive, and 
prenatal testing for facioscapulohumeral muscular dystrophy: diagnostic approach for sporadic and familial dystrophy: diagnostic approach

33 Lunt P, Jardine PE, Koch MC, et al. Correlation between fragments size at D4F104S1 and age at onset or at wheelchair use, with a possible generational effect, accounts for much phenotypic variation in $4 \mathrm{q} 35$ facioscapulohumeral muscular dystrophy (FSHD). Hum Mol Genet 1995;4:951-8. 34 Zatz M, Marie SK, Passos-Bueno MR, et al. High proportion of new mutations and possible anticipation in Brazilian facioscapulohumeral muscular dystrophy families. Am f Hum Genet 1995;56:99-105.
35 Tawil R, Forrester Y, Griggs RC, Mendell Y, Kissel Y. Evidence for anticipation and association of deletion size with severity in facioscapulohumeral muscular dystrophy. Ann Neurol 1996;39:744-8.

36 La Spada AR, Paulson HL, Fischbeck KH. Trinucleotide repeat expansion in neurological disease. Ann Neurol 1994; 36:814-22.

37 Arahata K, Ishihara $\mathrm{T}$, Fukunaga $\mathrm{H}$, et al. Inflammatory response in facioscapulohumeral muscular dystrophy (FSHD): immunocytochemical and genetic analysis. Muscle Nerve 1995;suppl 2:56-66. 